Falah: Jurnal Ekonomi Syariah

(p)ISSN: 2502-3918; (e)ISSN: 2502-7825

Vol 4, No 2 (Agustus 2019), pp.184-193

DOI: https://doi.org/10.22219/jes.v4i2.9875

\title{
Sistem Bagi Hasil Mudharabah Sebagai Mekanisme Self Regulating terhadap Kenaikan Upah Minimum Regional Pada UMKM Puti Minang Group (PtM)
}

\author{
Heru Wahyudi \\ Program Studi Ekonomi Pembangunan, Fakultas Ekonomi dan Bisnis, \\ Universitas Lampung \\ Email: Heru.wahyudi@feb.unila.ac.id
}

\begin{abstract}
Conflicts regarding tariff transitions and wages often occur in Indonesia. On the other hand, SMEs have an important role in efforts to improve the welfare of the community. This study aims to discuss selfregulating the results (mudharabah) of regional minimum wage increases at the MSME Puti Minang Group (PtM) successfully overcoming wage conflicts with Mudharabah. This research is a skin research carried out at PtM MSMEs in 6 Regencies in Lampung Province. The processed data is primarily based on the data for the result in PtM. In general, profit sharing (Mudharabah) at PTM in 2016 exceeded regional minimum wages. Based on the output value, it can be seen that the P-Value $=0,000$, means smaller than the value $\alpha=0.05$, so Ho is rejected and accept Ha. For users (Mudharabah) of PTM in 2016 is greater than the UMR in 2016. PtM wage system using profit sharing (Mudharabah), can provide regional minimum wage standard (UMR) in Lampung in 2016, with an increase of 2016 UMR of 13\% from UMR 2015. These results are evidence that a UMR increase of $13 \%$, the profit-sharing system (Mudharabah) at PTM still has the ability to adapt (self-regulate) to the increase in UMR.
\end{abstract}

Keywords: Self regulating, Profit Sharing, Wages, MSME. 


\begin{abstract}
ABSTRAK
Konflik perihal mekanisme dan tarif pengupahan seringkali terjadi di Indonesia. Di sisi lain, UMKM memiliki peran penting dalam upaya meningkatkan kesejahteraan masyarakat. Penelitian ini bertujuan untuk menguji self regulating bagi hasil (mudharabah) terhadap kenaikan upah minimum regional pada UMKM Puti Minang Group (PtM) managed to overcome the wage conflict with Mudharabah. Penelitian ini adalah kulitatif dengan pendekatan studi kasus yang dilakukan pada UMKM PtM di 6 Kabupaten di Propinsi Lampung. Data yang diolah adalah primer berdasarkan data bagi hasild di PtM. Secara umum, bagi hasil (Mudharabah) pada PtM di tahun 2016 melebihi upah minimum regional. Berdasarkan nilai output, terlihat nilai $\mathrm{P}-$ Value $=0,000$, berati lebih kecil dari nilai $\alpha=0,05$, sehingga Ho ditolak dan terima Ha. Artinya bagi hasil (Mudharabah) PtM tahun 2016 lebih besar dari pada UMR tahun 2016. Sistem pengupahan PtM dengan menggunakan bagi hasil (Mudharabah), dapat memberikan upah melebihi standar upah minimul regional (UMR) di Lampung pada tahun 2016, dengan kenaikan UMR tahun 2016 13\% dari UMR 2015. Hasil ini menjadi bukti bahwa sekalipun terjadi kenaikan UMR sebesar 13\%, sitem bagi hasil (Mudharabah) pada PtM tetap memiliki kemampuan adaptasi (self regulating) terhadap kenaikan UMR.
\end{abstract}

Kata Kunci: Penyesuaian Mandiri, Bagi Hasil, Upah, UMKM.

\title{
1. Pendahuluan
}

Pemerintah bertanggungjawab mewujudkan kesejahteraan rakyatnya. Membuat serangkaian peraturan yang dapat memastikan pemenuhan kebutuhan seluruh masyarkat adalah sebuah kewajiban pemerintah dalam Islam (Huda, 2012). Kesejahteraan rakyat terutama buruh tercermin dari upah yang diterima. Pemerintah membuat peraturan upah minimum (UMR). UMR sebagai upah yang mencerminkan kehidupan yang layak (sejahtera secara ekonomi). Asumsi manfaat UMR berlaku dalam kondisi ideal. Kenaikan UMR dapat meningkatkan penawaran tenaga kerja, artinya seseorang dapat menawarkan tenaganya kepada perusahaan daripada berwirausaha mandiri apabila ada kenaikan UMR (Sholeh, 2005). Menurut Pratomo (2011) pelaksanaan kebijakan upah minimum sesuai dengan UUD 1945 pasal 27 ayat 2 tentang penghidupan yang layak.

Menurut Agustine (2013), secara hukum Upah minimum yang ditetapkan oleh pemerintah merupakan jaring pengaman agar perusahaan minimal membayarkan upah dengan harapan kebutuhan dasar bagi kehidupan pekerja relatif mendekati terjangkau. Buruh yang menerima UMR dapat meningkat statusnya sehingga tidak tergolong miskin seperti penelitian di Riau (Riva, 2014). Menurut Komro, (2016) kenaikan upah minimum dolar di atas tingkat upah federal dikaitkan dengan penurunan berat badan dengan berat badan turun $1 \%$ sampai $2 \%$ dan penurunan angka kematian paska melahirkan sebesar $4 \%$. 
Kondisi ideal yang menjadi syarat berlakunya UMR tidak pernah terjadi dalam kenyataan (Gittings, 2016). Pengusaha menginginkan upah minimum yang murah karena upah dipandang sebagai beban bagi pengusaha, sedangkan buruh menghendaki upah minimum yang tinggi karena upah adalah penghasilan, dari kondisi inilah maka UMR selalu konflik (Zubair, 2015). Sistim upah dalam produksi dapat selalu menimbulkan konflik dan kondisi pengangguran seperti yang dinyatakan oleh Keynes, bahwa "kekakuan upah (wege rigidity) menyebabkan kegagalan self regulating",

Mudarabah berasal dari kata 'darbun' berarti memukul atau berjalan. Pengertian memukul atau berjalan ini lebih tepatnya adalah proses seorang memukulkan kakinya dalam menjalankan usaha (Hakim, 2015). Secara teknis, mudarabah adalah akad kerja sama usaha antara dua pihak dimana pihak pertama (sahibul mal) menyediakan seluruh modal, sedangkan pihak lainnya (mudarib) menjadi pengelola. Keuntungan usaha secara mudarabah dibagi menurut kesepakatan yang yang dituangkan dalam kontrak, sedangkan apabila rugi ditanggung oleh pemilik modal selama kerugian itu bukan akibat kelalaian si pengelola (Antonio, 2002).

Beberapa penelitian terkait dampak buruk upah minimum regional (UMR), hal ini berpengaruh negatif terhadap kesejahteraan penduduk, sebab peningkatan upah minimum memberi kontribusi pada pengangguran (Basu, 1999), (Couch, 1999), (Makasau, 2007), (Nugroho, 2012), (Pitartono, 2012), (Putro, 2013). Menurut Dube (2016), upah minimum memiliki efek negatif yang cukup besar terhadap serapan tenaga kerja, disebabkan penentuan upah minimum, maka perusahaan dapat membuat kondisi kerja lebih keras (Fraja, 1999). Menurut Macpherson (2002), berlakunya upah minimum dapat menghasilkan kira-kira 131.000 sampai 222.000 pekerja yang kehilangan pekerjaan. Menurut Fernandez (2016) di tingkat Uni Eropa (EU), terdapat perdebatan mengenai koordinasi upah minimum. UMR merupakan model pengupahan kapitalis, dimana upah adalah beban bagi pengusaha. UMR selalu mengalami konflik pengupahan yaitu pengusaha menginginkan UMR yang rendah, sedangkan serikat buruh menuntut UMR yang lebih tinggi lagi.

UMR di Propinsi Lampung juga selalu mengangalami kenaikan. Tahun 1996 nilai UMR Rp. 114.000 dan tahun 2016 UMR Rp. 1.581.000 bearti UMR selama 20 tahun naik sebesar $1.286 \%$, namun konflik pengupahan tidak selesai. Dampak UMR bagi Usaha Mikro, Kecil, dan Menengah (UMKM) akan berahir fatal yaitu bubarnya perusahaan karena tidak mampu membayar upah minimum padahal UMKM merupakan sektor yang urgen dalam perekonomian Indonesia (Amalia, 2009). UMKM Rumah Makan Puti Minang (PtM) di 6 kabupaten Propinsi Lampung berhasil mengatasi konflik pengupahan dan sukses dalam bisnisnya dengan menerapkan Mudharabah yaitu model distribusi pendapatan berupa bagi hasil usaha (Profit-loss sharing). Tujuan dari tulisan ini adalah bagaimanakah 
Mudharabah dapat menjadi instrument kemandirian ekonomi Islami (self regulating) pada Usaha Mikro Kecil dan Menengah (UMKM).

\section{Metode Penelitian}

Penelitian ini merupakan penelitian studi kasus. Lokasi penelitian dilakukan pada UMKM Rumah Makan Puti Minang (PtM) terletak di 6 (enam) kabupaten/kota di Provinsi Lampung. Data yang digunakan adalah laporan bagi hasil dari 392 informan dan UMR Propinsi Lampung. Sumber data dari bagian keuangan PtM, dan BPS Propinsi Lampung. Analisis data dilakukan menggunakan uji hipotesis dengan alat uji beda rata rata dengan dua sampel (independent sampel t test) dan analisis Diskriptif (Mean, Maximum, Minimum).

\section{Analisis dan Pembahasan}

UMR Propinsi Lampung tahun 2016 adalah Rp.1.581.000, dengan menggunakan softwere minitab 15 melalui uji beda dua sample (Two-Sample TTest ), maka diperoleh output nilai P-Value $=0,000$, berati lebih kecil dari nilai $\alpha$ $=0,05$, sehingga Ho ditolak dan terima Ha. Artinya jadi benar bahwa rata-rata uang bagi hasil Mudharabah PtM tahun 2016 lebih besar dari pada UMR tahun 2016. Jadi secara statistik dengan tingkat kepercayaan $95 \%$ dapat dipastikan nilai uang bagi hasil PtM pada tahun 2016 melebihi UMR tahun2016, jadi semua buruh PtM memperoleh uang bagi hasil tahun 2016 lebih besar dari pada UMR 2016. Hasil penelitian ini menjadi bukti riil pernyataan Ediarno bahwa Mudharabah bagi hasil akan memiliki self regulating.

Berdasarkan perhitungan deskriptif komparatif seperti yang tertera pada Tabel 1.1 diperoleh informasi penting sebagai berikut : dilihat dari nilai Mean, terdapat 13 PtM memiliki Mean dua sampai tiga kali nilai UMR. Berdasarkan nilai Maximum Mudharabah PtM Pringsewu dan Mudharabah PtM Haji Mena sebanyak enam kali nilai UMR 2016. Berdasarkan nilai Minimum seluruh uang bagi hasil Mudharabah lebih besar dari pada UMR 2016, bahkan uang bagi hasil Mudharabah paling kecil sekalipun telah melebihi UMR 2016. Terdapat uang bagi hasil Mudharabah terkecilnya sama dengan tiga kali UMR seperti PtM Supplier. PtM Suplyer ini sangat fenomenal karena baru memulai bagi hasil langsung peringkat 3 secara rata-rata. Pimpinan PtM dengan pendapatan paling kecil berada di PtM Hj. ir. Pahoman dengan rata-rata pendapatan per bulan 4.258.000, rupiah setara dengan 3 kali $(2,7 \%)$ nilai UMR 2016. RU dengan pendapatan paling rendah pada PtM Labuhan Ratu sebesar 1758 ribu Rupiah. 
Tabel 1.1

Analisis Komparatif Pendapatan Bagi Hasil Mudharabah dengan Upah Minimum Regional (UMR) Tahun 2016 (dalam Ribuan)

\begin{tabular}{|c|c|c|c|c|c|c|c|c|c|c|}
\hline Nama PtM & $\begin{array}{c}\text { UMR } \\
2016\end{array}$ & Mean & $\Delta$ & $\%$ & $\operatorname{Max}$ & $\Delta$ & $\%$ & Min & $\Delta$ & $\%$ \\
\hline RPA & 1581 & 3069 & 1488 & 94 & 4309 & 2728 & 173 & 2114 & 533 & 34 \\
\hline Darrusalam & 1581 & 3729 & 2148 & 136 & 6213 & 4632 & 293 & 2752 & 1171 & 74 \\
\hline Hj.ir.Pahoman & 1581 & 2681 & 1100 & 70 & 4258 & 2677 & 169 & 1919 & 338 & 21 \\
\hline Hj.ir.Pengajaran & 1581 & 4309 & 2728 & 173 & 6954 & 5373 & 340 & 2559 & 978 & 62 \\
\hline Lab.Ratu & 1581 & 3036 & 1455 & 92 & 5334 & 3753 & 237 & 1758 & 177 & 11 \\
\hline Tj Seneng & 1581 & 3839 & 2258 & 143 & 5741 & 4160 & 263 & 2798 & 1217 & 77 \\
\hline Palapa & 1581 & 4004 & 2423 & 153 & 6526 & 4945 & 313 & 2921 & 1340 & 85 \\
\hline Gd. Meneng & 1581 & 3493 & 1912 & 121 & 5083 & 3502 & 222 & 2685 & 1104 & 70 \\
\hline Sumur Batu & 1581 & 3720 & 2139 & 135 & 6178 & 4597 & 291 & 2755 & 1174 & 74 \\
\hline Pahoman & 1581 & 3784 & 2203 & 139 & 6668 & 5087 & 322 & 1779 & 198 & 13 \\
\hline pesawaran & 1581 & 4695 & 3114 & 197 & 7799 & 6218 & 393 & 2959 & 1378 & 87 \\
\hline Pringsewu & 1581 & 5786 & 4205 & 266 & 10607 & 9026 & 571 & 3071 & 1490 & 94 \\
\hline Hjmena & 1581 & 5554 & 3973 & 251 & 10591 & 9010 & 570 & 2553 & 972 & 61 \\
\hline Cdmas & 1581 & 4018 & 2437 & 154 & 6359 & 4778 & 302 & 2828 & 1247 & 79 \\
\hline Suppyer & 1581 & 4739 & 3158 & 200 & 6831 & 5250 & 332 & 3634 & 2053 & 130 \\
\hline Bdjaya & 1581 & 3565 & 1984 & 125 & 5061 & 3480 & 220 & 2710 & 1129 & 71 \\
\hline
\end{tabular}

Sumber: Data diolah, 2017

Keterangan:

$\Delta$ : perubahan bila dibandingkan dengan UMR 2016 (1.581.000).

$\%$ : persentase dari perbandingan dengan UMR 2016 (1.581.000).

Dari Tabel di atas, diketahui bahwa PtM dengan bagi hasil Mudharabah nya memberikan uang bagi hasil melebihi UMR tahun 2016 padahal UMR 2016 telah naik $1.286 \%$ selama 20 tahun, naik 13\% dari UMR 2015. Hasil ini menjadi bukti bahwa sekalipun terjadi kenaikan UMR sebesar 13\%, bagi hasil Mudharabah PtM tetap memiliki self regulating atau kemampuan adaptasi terhadap kenaikan UMR, bahkan terdapat Mudharabah dengan nilai bagi hasil paling rendah sebanyak tiga kali lipat UMR 2016 seperti pada PtM Suplyer. Hasil penelitian ini sesuai dengan hasil penelitian Setiawan (2016) bahwa sistem bagi hasil bekerja lebih baik dalam menghasilkan profitabilitas, lebih adil dalam mendistribusikan upah, dan menciptakan produktivitas lebih tinggi. 


\subsection{Perbandingan Nilai Uang Mudharabah Tahun 2015 dengan Tahun 2016}

Kemampuan self regulating diantara PtM Mudharabah dijelaskan pada tabel 1.2 di bawah ini. Dinyatakan bahwa berdasarkan perbandingan nilai Mean diketahui mayoritas Mudharabah PtM mengalami peningkatan dari 16 PtM hanya dua PtM yang mengalami kemunduran yaitu PtM Gedung Meneng dan Lab. Ratu.

Tabel 1.2

Analisis Komparatif Pendapatan Bagi Hasil Mudharabah Tahun 2015 dengan tahun 2016 (dalam Ribuan)

\begin{tabular}{lrrrrrrrrrr}
\hline \multirow{2}{*}{ Nama PtM } & \multicolumn{3}{c}{ Mean } & \multicolumn{3}{c}{ Maximum } & \multicolumn{3}{c}{ Minimum } \\
\cline { 2 - 10 } & $\mathbf{2 0 1 5}$ & $\mathbf{2 0 1 6}$ & $\Delta$ & $\mathbf{2 0 1 5}$ & $\mathbf{2 0 1 6}$ & $\Delta$ & $\mathbf{2 0 1 5}$ & $\mathbf{2 0 1 6}$ & $\Delta$ \\
\hline RPA & 3068 & 3069 & 1 & 4212 & 4309 & 97 & 2381 & 2114 & -267 \\
\hline Darusalam & 2587 & 3729 & 1142 & 3913 & 6213 & 2300 & 1718 & 2752 & 1034 \\
\hline hj.ir pahoman & 2471 & 2681 & 210 & 5003 & 4258 & -745 & 1710 & 1919 & 209 \\
\hline hj.ir. Pengajaran & 2253 & 4309 & 2056 & 4542 & 6954 & 2412 & 1739 & 2559 & 820 \\
\hline Lab. Ratu & 3234 & 3036 & -198 & 5056 & 5334 & 278 & 2058 & 1758 & -300 \\
\hline tj.seneng & 2894 & 3839 & 945 & 4976 & 5741 & 765 & 2102 & 2798 & 696 \\
\hline Palapa & 3293 & 4004 & 711 & 4973 & 6526 & 1553 & 2330 & 2921 & 591 \\
\hline Gd. Meneng & 4279 & 3493 & -786 & 7513 & 5083 & -2430 & 2782 & 2685 & -97 \\
\hline Sumur batu & 2968 & 3720 & 752 & 5215 & 6178 & 963 & 1702 & 2755 & 1053 \\
\hline Pahoman & 2993 & 3784 & 791 & 5719 & 6668 & 949 & 1723 & 1779 & 56 \\
\hline Pesawaran & 3981 & 4695 & 714 & 7262 & 7799 & 537 & 2818 & 2959 & 141 \\
\hline Pringsw & 4142 & 5786 & 1644 & 8004 & 10607 & 2603 & 2076 & 3071 & 995 \\
\hline Hjmena & 4276 & 5554 & 1278 & 9611 & 10591 & 980 & 1760 & 2553 & 793 \\
\hline Cdmas & 3470 & 4018 & 548 & 7050 & 6359 & -691 & 1805 & 2828 & 1023 \\
\hline
\end{tabular}

Sumber : Data diolah, 2017

Berdasarkan data di atas, perbandingan nilai Maximum Mudharabah mayoritas PtM mengalami kemajuan, dari 16 PtM hanya tiga PtM yang mengalami kemunduran yaitu PtM Ir. Pahoman, Gedung Meneng dan Candi mas. Berdasarkan nilai Minimum semua PtM mengalami Peningkatan pendapatan bagi hasil Mudharabah, hanya tiga PtM yang mengalami penurunan nilai minimum yaitu RPA, Lab.Ratu, dan Gd.Meneng. Jadi kesimpulan secara umum dari 16 PtM sebanyak 14 PtM atau (88\%) mengalami kemajuan yang terlihat dari perubahan positif nilai Mudhorobah yang diperoleh, dua PtM mengalami penurunan Mudhorobah. Penurunan Mudharabah tetap masih di atas UMR yang sudah naik 13\%. Hasil penelitian ini sesuai dengan Ibn Khaldun "profit sharing sebagai cara yang adil untuk pembagian surplus produksi”.

Upah menurut pemikiran barat merupakan beban bagi pengusaha. Pengusaha menginginkan UMR yang rendah, sedangkan serikat buruh menuntut UMR yang lebih tinggi lagi. Sebagaimana dinyatakan oleh Ediarno (2016) bahwa sistem upah

Falah: Jurnal Ekonomi Syariah 
membuat ekonomi tidak self regulating, resiko krisis yang tinggi, konflik abadi laba-upah. Konflik pengupahan ini akan selalau muncul terutama setiap mempringati hari buruh internasional.

Di sisi lain, Islam memperkenalkan solusi pengupahan berupa distribusi pendapatan dengan bagi hasil (profit-loss sharing) dengan akad syirkah atau mudharabah. Bagi hasil adalah proporsi pembagian hasil usaha dalam ukuran prosentase atas kemungkinan keuntungan/kerugian riil yang akan diperoleh pihakpihak yang bekerja sama. Jumlah nominal bagi hasil akan berfluktuasi sesuai dengan keuntungan riil dari pemanfaatan dana. Model bagi hasil sangat menghargai nilai manusia dan sesuai dengan fitrah berusaha, dimana hasil riil yang akan menjadi patokan dalam pengupahan.

Model bagi hasil tidak menjadikan upah buruh sebagai beban, karena yang menjadi biaya sesungguhnya adalah biaya-biaya yang muncul dalam rangka menghasilkan laba. Tanpa menganggung biaya upah berarti pengusaha akan punya kesempatan bayak untuk pengembangan usaha/ekspansi usaha. Bagi hasil akan memotivasi karyawan untuk mengasilkan laba yang paling banyak karena semakin besar laba yang diperoleh akan berdampak pada besarnya bagi hasil yang diterima, dan semakin kecil laba yang diperoleh, maka semakin sedikit bagi hasil yang diterima. Apabila buruh mendapat bagian besar maka pengusaha/pemodal juga akan memperoleh bagian laba yang banyak.

Hasil ini menjadi bukti secara kongkrit tentang benarnya pendapat bahwa Mudhorobah memiliki self regulating, dengan menggunakan model Mudhorobah semua sumberdaya harus digunakan dalam kondisi full employment, tidak boleh ada yang menganggur atau mubazir. Semua sumberdaya harus bersinergi agar diperoleh bagian bagi hasil yang diharapkan. Hasil penelitian menunjukkan bahwa system bagi hasil Mudharabah pada UMKM PtM menjadi instrumen kemandirian ekonomi Islami (self regulating) terhadap kenaikan UMR. Usaha yang dikelola dengan pola bagi hasil apabila tidak bersinergi dengan bagus maka akan mempengaruhi hasil usaha yang akan berdampak pada bagi hasil yang akan diterima. Hasil penelitian ini sesuai dengan penyataan Nafik (2008) sistem mudhorobah merupakan alat yang akan menghasilkan efisiensi yang lebih besar bagi para pekerja industri, karena ada bagian keuntungan yang mereka peroleh diharapkan akan lebih giat dan tekun untuk memelihara barang-barang dan alatalat produksi. Sehingga ketika mereka semakin giat bagian untuk mereka akan meningkat dan pengusaha memperoleh hasil keuntungan yang meningkat.

Hasil penelitian ini menjadi bukti riil keunggulan mudharabah seperti pendapat Qurashi (2007), bahwa dengan menerapkan sistem mudharabah akan diperoleh banyak manfaat, diantaranya adalah: pertama, sistem ini dapat memberikan solusi bersama antara pekerja dan pemodal, mengangkat derajat pekerja dengan mengubahnya dari sekedar alat dalam proses produksi ke posisi mitra. Kedua, sistem ini dapat meningkatkan produktifitas pekerja, serta mendorong minat pekerja terhadap kesuksesan perdagangan dan rencana yang ada 
ditangannya. Ketiga, sistem ini dapat menumbuhkan pendapatan pekerjaan dengan menambah porsi yang diperoleh pada saat pencarian laba, maka mudharabah membantu dalam menabung atau menghadapi pembelanjaanpembelanjaan yang tidak biasa. Keempat, sistem ini dapat mencegah pengangguran dengan membangun hubungan-hubungan yang langgeng diantara pemilik harta dan pekerja. Kelima, sistem ini dapat membuka pintu kerjasama ekonomi antara pemilik modal dan pekerja atas landasan yang adil. Keenam, sistem ini dapat menghindarkan perluasan modal individu karena keuntungan itu harus terdistribusi dengan cara yang adil diantara kedua belah pihak.

\section{Kesimpulan}

Berdasarkan pembahasan di atas, dapat disimpulkan bahwa system mudharabah memiliki kemampuan untuk menyesuaikan diri dan memberikan keuntungan lebih besar di bandingkan dengan sistem Upah Minimum Regional (UMR). Hal ini terlihat dengan hasil penelitian, bahwa rata-rata uang bagi hasil mudharabah di PtM tahun 2016 melebihi upah minimum regional (UMR) tahun 2016 di Lampung meskipun telah mengalami kenaikan. Demikian pula, semua bagi hasil mudharabah tahun 2016 lebih besar daripada bagi hasil mudharabah 2015, artinya bagi hasil mudharabah memiliki self rulating terhadap kenaikan UMR dan memiliki auto self regulating diantara bagi hasil. berdasarkan kesimpulan ini maka dapat memberi masukan kepada Pemerintah agar sistem ini dapat menjadi kebijakan model bagi hasil sebagai penentu upah buruh sektor UMKM dan non UMKM.

\section{Daftar Pustaka}

Agustine, Michele. 2013. Pemberlakuan UMK (Upah Minimum Kota/Kabupaten) terhadap Kesejahteraan Pekerja/Buruh”, Jurnal Hukum Perdata. Universitas Udayana.

Amalia, Euis. 2009. Keadilan Distributif Dalam Ekonomi Islam. Jakarta. Rajawali Press.

Anotnio. M. Syafi'i. 2001. Bank Syariah Dari Teori Ke Praktik. Jakarta: Gema Insani.

Ash Siddiqieqy, Muhammad. 1996. Kemitraan Usaha dan Bagi Hasil dalam Hukum Islam, Dana Bakti Prima Yasa.Yogyakarta

Basu.1999. Household labour Supply, Unemployment, and Minimum Wage World Bank Policy Paper 2049. Woshinton

Bappenas, 2001, Upah Minimum; Sebuah Kajian tentang Dampaknya Terhadap Penciptaan Lapangan Kerja Di Masa Krisis. Bappenas. Jakarta.

Chapra, M.Umer. 2000. Sistim Moneter Islam. Jakarta. Gema Insani Press

Couch, 1999, Distribution and Employment Infact of Raising RMW. FRBSF Economic Latter.Sanfransisco.CA 94120.

Dube, Arindrajit; Leser, T. William; Reich, Michael. 2016. Minimum wage shocks, employment flows, and labor market frictions. Journal of Labor Economics, 34(3): 663-704.

Falah: Jurnal Ekonomi Syariah 
Ediarno, 2016, Teori Ekonomi Bagi Hasil, Penerbit A4, Tanggerang.

Fernandez-Macias, Enrique; Vacas-Soriano, Carlos. 2016. A coordinated European Union minimum wage policy?. European Journal of Industrial Relations, 22(2): 97-113.

Gittings, R. Kaj; Schmuttie, Ian M. Getting handcuffs on an octopus: Minimum wages, employment, and turnover. ILR Review, 2016, 69(5): 1133-1170.

Hakim, Rahmad. 2015. Pembangunan Ekonomi Islam Pada Perbankan Syari'ah: Telaah Beberapa Problem Dalam Transaksi Mudarabah Kontemporer. Islamic Economics Journal, 1(1): 61-83

Huda, Nurul, 2012. Keuangan Publik Islami pendekatan Teoritis dan Sejarah, Kencana. Jakarta.

Jusmaliani, 2005, Mengenal kembali Kegiatan Ekonomi Berbasis Bagi Hasil. P2E LIPI. Jakarta.

Karim, Adiwarman, 2007. Bank Islam “Analisis Fiqih dan Keuangan”, PT. Raja Grafindo Persada, Jakarta.

Komro, Kelli A. The effect of an increased minimum wage on infant mortality and birth weight. American journal of public health, 2016, 106(8): 1514-1516.

Macperson, 2002, The Employment Infact of A comprehensive Living Wage Laweridence from Florida. Employmen Policies Institute. Florida State University.

Makasau, Andi, 2009. "Pengaruh Implementasi Kebijakan Upah Minimum pada Hubungan Kerja Perusahaan dengan Pekerja di Kabupaten Bandung” Jurnal Ilmu Administrasi Negara, 9(1): 22 - 35

Muhammad. 2002. Kebijakan Fiskal dan Moneter dalam Ekonomi Islam. Jakarta: Salemba Empat.

Nafiq, Muhammad, 2008. Model Perhitungan Nisbah Pada Sistem Bagi Hasil. Unair. Surabaya.

Nugroho, 2012. Pengaruh Upah Minimum Terhadap Pengangguran Terbuka. Jurnal Economi Diponegoro. Semarang. FEB. Universitas Diponegoro.

Pitartono, Ronny. 2012. Analisis Tingkat Pengangguran di Jawa Tengah Tahun 1997-2010. Tesis. Universitas Diponegoro.

Pratomo. 2011. Kebijakan Upah Minimum Untuk Perekonomian Yang Berkeadilan: Tinjauan UUD 1945'. Journal of Indonesian Applied Economics Vol. 5 No. 2 Oktober 2011, 269-285.Universitas Brawijaya.

Putro, Akbar. 2013. Analisis Pengaruh PDRB, Tingkat UMK, Tingkat Infasi dan Beban/Tanggungan Penduduk Terhadap Pengangguran Terbuka di Kota Malang Periode Tahun 1990-2010. Diponegoro jurnal of economic. Volume 2, Nomor 3, Tahun 2013.

Qorashi, Syarief Baqir. 2007. Keringat Buruh, Hak dan Peran Pekerja Dalam Islam. Al-Huda. Jakarta.

Riva Vinny Alvionita, 2014. Pengaruh Tingkat Pengangguran Dan Tingkat UMP Terhadap Tingkat Kemiskinan Di Provinsi Riau. JOMFEKON. 1.

Ricardo, David, on the Principle of Political Economy and Taxation, Chafter 5, London. Jhon Murray, Library of Economics and Library.

Saget. 2001. Is The Minimum Wages an Effective Tool to Promote Decen Work and Reduce Poverty? The experience or selected Developing Countries. Employmen Paper 2001/13. International Labour Office. 
Setiawan, Deny. 2016. Comparison on the Effect of Profit Sharing System between Islamic and Conventional System on Profitability, Wages, and Productivity (A Study on Padang Restaurant in Pekanbaru). American Journal of Economics, 6(5): 270-279.

Shaukat, Mughees; Hasan, Zubair; Al Habshi, Datuk Syed Othman. 2014. Financing Economic Growth with Stability from Islamic Perspective. Journal of Islamic Business and Management. 4(2): 15-62.

Shikh, Salman Ahmed. 2015. A Comparative Study of Views and Role of Labor in Marxian, Mainstream and Islamic Economics.

Sholeh, Maimun. 2005. Dampak Kenaikan Upah Minimum Propinsi Terhadap Kesempatan Kerja (Propinsi Jawa Tengah)" Jurnal Ekonomi \& Pendidikan, 2(2). Desember 2005

Zubair, Hasan. 2007, Labous as a Source of Value and Capital Formulation : ibnu Kaldun, Ricardho, and Marx- Comparison. Journal Ekonomi Islam. Vol 20(2). 49.

Distribusional Equity in Islam, in Distributive Justice and Need Fulfilment in an Islamic Economy, Edited By Munawar Iqbal, Leicer, UK: The Islamic Foundation, 35-90. 